\title{
PENGARUH MALEATED NATURAL RUBBER (MNR) TERHADAP SIFAT MEKANIK VULKANISAT KARET DENGAN FILLER ARANG AKTIF TEMPURUNG KELAPA
}

\section{THE EFFECT OF MALEATED NATURAL RUBBER (MNR) TOWARDS MECHANICAL PROPERTIES OF RUBBER VULANIZATE WITH THE COCONUT SHELL CHARCOAL FILLER}

\author{
Popy Marlina $^{1^{*}}$ dan Hari Adi Prasetya ${ }^{1}$ \\ ${ }^{1}$ Balai Riset dan Standardisasi Industri Palembang \\ ${ }^{1}$ Jalan Perindustrian II No. 12 Sukarami KM. 09 Palembang, Sumatera Selatan, Indonesia 30152 \\ * main contributor and coresponding author \\ ${ }^{1}$ e-mail : popy_marlina@yahoo.co.id
}

Diterima: 08 Maret 2020; Direvisi: 10 Juni 2020 - 14 Juni 2020; Disetujui: 17 Juni 2020

\begin{abstract}
Abstrak
Penelitian ini bertujuan memanfaatkan limbah tempurung kelapa sebagai bahan pengisi alternative vulkanisat karet. Peningkatan karakteristik vulkanisat karet yang dihasilkan, dilakukan dengan cara menambahkan bahan penghubung maleated natural rubber (MNR) yang akan berperan sebagai material penghubung, antara bahan pengisi arang tempurung kelapa yang bersifat polar dan karet alam yang non polar. Penelitian dilakukan dalam skala laboratorium dengan faktor perlakuan perbandingan jumlah bahan pengisi arang aktif tempurung kelapa (ATK) dan carbon black (CB) 0/45; 22,5/22,5; 45/0 phr dan waktu penyimpanan 1 hari, 2 hari, dan 3 hari, pengulangan setiap perlakuan sebanyak 3 (tiga) kali. Karakteristik arang tempurung kelapa yang diamati kadar karbon terikat hasil aktivasi arang aktif tempurung kelapa dan perubahan sifat mekanik vulkanisat karet meliputi kekerasan, tegangan putus dan perpanjangan putus diamati sebelum dan sesudah pengusangan. Kadar karbon terikat hasil penelitian ini sebesar 80\%, sesuai dengan standar SNI 06-37301995, kualitas arang aktif minimal 65\%. Nilai kekerasan, tegangan putus, dan perpanjangan putus, tidak mengalami perubahan signifikan sebelum dan sesudah pengusangan dengan penambahan maleated natural rubber (MNR).
\end{abstract}

Kata kunci : Arang aktif tempurung kelapa, maleated natural rubber, vulkanisat karet.

\begin{abstract}
This study aims to utilize coconut shell waste which can be used as an alternative filler of rubber vulcanisate. Increasing the characteristics of rubber vulcanisate was performed by adding maleated natural rubber (MNR) as coupling agent material between the coconut shell charcoal filler material that is polar and natural rubber that is non polar. The study was conducted in a laboratory scale with a treatment factor comparing the loading of active coconut shell charcoal (ATK) and carbon black (CB) 0/45; 22.5/22.5; 45/0 phr and storage time of 1 , 2 and 3 days, each treatment was repeated 3 (three) times. The characteristics of coconut shell charcoal observed by the carbon content bound to the results of activated coconut shell charcoal and changes in the mechanical properties of rubber vulcanisate include hardness, tensile strength and elongation at break observed before and after aging. Carbon contents bound to the result of research to $80 \%$, meets the standards set by SNI 06-3730-1995, the quality of activated charcoal that is equal to 65\%. Hardness, tensile strength and elongation at break, did not experience significant changes before and after aging with the addition of maleated natural rubber (MNR).
\end{abstract}

Keywords : coconut shell activated charcoal, maleated natural rubber, rubber vulcanisate. 


\section{PENDAHULUAN}

Industri barang jadi karet merupakan konsumen besar carbon black yang digunakan sebagai bahan pengisi penguat untuk memberikan karakteristik tertentu pada produk karet seperti kekerasan dan kekuatan. Penggunaan bahan pengisi pada kompon karet mempengaruhi juga karakteristik vulkanisasi. Bahan pengisi memiliki kemampuan meningkatkan sifat produk karet. Kemampuan tersebut dipengaruhi oleh karakteristik alami karet, ukuran partikel dan jumlah pengisi yang digunakan.

Peningkatan dengan jumlah tertentu dari bahan pengisi dapat menyebabkan perbaikan sifat vulkanisat. Carbon black merupakan jenis bahan pengisi sintetis hasil samping dari proses pengolahan minyak bumi, bersifat tidak biodegradable. Alternatif untuk mengatasi penggunaan bahan pengisi dari bahan mineral pengolahan minyak bumi, dengan memanfaatkan bahan pengisi alami.

Pemanfaatan sumber daya alam lokal sebagai bahan pengisi, salah satunya adalah arang tempurung kelapa yang mempunyai sifat terbarukan, biaya murah dan ketersediaan mudah didapatkan, mudah untuk diaplikasikan dalam komposit karet. Tempurung kelapa mengandung serat selulosa 22 hingga 26\% (Yusnaini dan Rodianawati, 2014; Sareena et al, 2012).

Pencampuran karet alam dengan bahan pengisi arang tempurung kelapa untuk meningkatakn degradasinya. Perbedaan kepolaran karet alam dana rang tempurung kelapa menyebabkan pencampuran tidak homogen. Peningkatkan kompatibilitas campuran, diperlukan bahan penghubung (coupling agent) yang dapat meningkatan interaksi antara bahan pengisi dengan matriks polimer. Perlakuan pada permukaan bahan pengisi mampu meningkatakan interface dan adhesi bahan pengisi dengan matriks polimer (Sareena et al, 2012).
Serat selulosa memiliki masalah kompatibilitas antara serat dan matriks karet. Serat alami bersifat hidrofobik karena banyaknya gugus hidroksi dan karenanya tidak cocok dengan matriks karet hidrofobik, yang menghasilkan komposit dengan sifat yang buruk (Artchomphoo and Rattanapan et al, 2013). Ikatan interface dapat ditingkatkan dengan mencangkokan serat menggunakan coupling agent. Penggunaan coupling agent telah dilakukan dalam banyak penelitian, seperti Mohammad et al, (2015); Cao et al (2012) menunjukkan bahwa, penambahan coupling agent dapat meningkatkan sifat komposit karet alam dan serat alam. Mulia et al (2015), penggunaan maleated natural rubber (MNR) sebagai coupling agent dapat meningkatkan sifat mekanik thermoset rubber. Marlina dan Prasetya (2017), penelitian penggunaan bahan pengisi abu dari sekam padi dan agen penghubung, menghasilkan kompon bantalan dermaga dengan karakteristik memenuhi persyaratan mutu bantalan dermaga. Penelitian Ismail et al, 2005, menggunakan MNR sebagai coupling agent pada komposit karet alam dan pengisi limbah kertas, hasil penelitian menghasilkan sifat tarik vulkanisat karet meningkat dengan semakin meningkatnya jumlah pengisi limbah kertas, dengan adanya MNR (Ismail et al., 2005). Penelitian Ujianto et al, 2017, menggunakan MNR sebagai bahan penghubung pada komposit karet alam dan serat kelapa. Hasil penelitian menunjukkan semakin tinggi konsentrasi MNR sampai 7 phr, menghasilkan peningkatan tegangan putus sampel karet.

Penelitian ini akan dikembangkan modifikasi bahan pengisi arang tempurung kelapa yang bersifat polar dan karet alam yang merupakan senyawa polar, dengan cara menambahkan bahan penghubung MNR. Belum pernah dilakukan penelitian arang dari tempurung kelapa untuk pengisi pada kompon karet, dengan menggunakan MNR sebagai bahan 
penghubung. Parameter percobaan yang dilakukan variasi jumlah arang tempurung kelapa dan carbon black dengan lama ppengusangan vulkanisat karet. Sifat mekanik dilakukan pengamatan ketahanan usang meliputi, kekerasan, tegangan putus, perpanjangan putus. Adanya MNR diharapkan dapat meningkatkan interaksi arang tempurung kelapa, carbon black dan karet alam sehingga meningkatkan sifat mekanik vulkanisat karet.

\section{BAHAN DAN METODE}

\section{Bahan}

Penelitian ini menggunakan bahan sebagai berikut, SIR 20 dari supplier PT. Prasidha Aneka Niaga TBK, karet sintetis EPDM, Maleat anhidrat (MAH), minyak minarex, sulfur, $\mathrm{ZnO}$, asam stearat, BHT, 6PPD, Mercaptodithiobenzothiazol (MBTS), CBS, carbon black FEF (Fast extrusion furnace) $\mathrm{N}-550$, retarder $\mathrm{PVI}$ dari Supplier PT. Bratachem. $\mathrm{H}_{3} \mathrm{PO}_{4}$ dan Aquadest dari PT. Dira Sonita.

\section{Peralatan}

Penelitian ini menggunakan peralatan sebagai berikut : timbangan analitik merk metler p1210 kapasitas $1200 \mathrm{~g}$, open mill L $40 \mathrm{~cm} \mathrm{D18 \textrm {cm }}$ kapasitas $5 \mathrm{~kg}$, pemotong kompon karet, alat press, glassware, oven, Desikator dan Furnace merk Memert.

\section{Metode Penelitian}

\section{Rancangan Percobaan}

Penelitian dilakukan variasi perlakuan sebagai berikut :

- Variasi bahan pengisi arang aktif tempurung kelapa (ATK) dan carbon black $(\mathrm{CB})=0 / 45 ; 22,5 / 22,5 ; 45 / 0$ (masing-masing dalam satuan phr (part hundred rubber).

- Lama pengusangan = 1 hari, 2 hari, 3 hari.

\section{Tahapan Kegiatan}

Proses Pengolahan Tempurung Kelapa Menjadi Karbon Aktif (Budiono et al., 2010)

Tempurung kelapa sebanyak $1 \mathrm{~kg}$ dibakar dalam dalam furnace pada temperatur $200^{\circ} \mathrm{C}$, dengan lama pembakaran 5 jam. Arang tempurng yang lolos ukuran mesh 400, dilakukan perendaman sebanyak 200 gram $\mathrm{H}_{3} \mathrm{PO}_{4}$ $4 \mathrm{M}$ dengan lama perendaman 10 jam. Campuran tersebut disaring dan dicuci dengan aquadest. Dilakukan pengeringan pada oven temperatur sekitar $110^{\circ} \mathrm{C}$ dengan waktu 3 jam. Kemudian campuran didinginkan dalam Desikator. Arang diaktifkan dengan metode kimiawi, dengan cara perendaman, lamanya 24 jam dalam larutan $\mathrm{H}_{3} \mathrm{PO}_{4} 10 \%$. Arang dimasukkan dalam furnace untuk proses aktivasi 120 menit, temperatur $800^{\circ} \mathrm{C}$. Arang aktif dilakukan pendinginan 24 jam. Arang aktif diayak dan diuji karbon karbon terikat (sesuai SNI arang aktif (SNI 063730-1995).

\section{Proses Pembuatan Vulkanisat Karet}

Tahapan pertama dilakukan penimbangan bahan-bahan yang dibutuhkan sesuai formulasi Tabel 1.

Tabel 1. Formulasi Kompon Karet

\begin{tabular}{lccc}
\hline \multirow{2}{*}{\multicolumn{1}{c}{ Formula }} & \multicolumn{3}{c}{ Perlakuan (phr) } \\
\cline { 2 - 4 } & P1 & P2 & P3 \\
\hline Karet SIR 20 & 100 & 100 & 100 \\
MNR (Maleat & 8 & 8 & 8 \\
Natural Rubber) & & & \\
ZnO & 5 & 5 & 5 \\
Asam stearat & 2 & 2 & 2 \\
CBS & 1,5 & 1,5 & 1,5 \\
Minyak Minarek & 1 & 1 & 1 \\
BHT & 1 & 1 & 1 \\
6PPD & 1 & 1 & 1 \\
MBTS & 1 & 1 & 1 \\
ATK & 0 & 22,5 & 45 \\
CB & 45 & 22,5 & 0 \\
\hline
\end{tabular}

\section{Pencampuran}

Pencampuran dalam gilingan terbuka (open mill), dengan tahapan sebagai berikut : Mastikasi SIR 20 dan MNR, masing- masing dengan waktu 3 menit. Pencampuran bahan pengisi ATK dan $\mathrm{CB}$, pelunak minyak minarek, Anti oksidan BHT dan 6PPD, aktivator $\mathrm{ZnO}$ dan asam stearate, bahan pencepat CBS dan MBTS dan vulkanisator sulfur, masing-masing digiling sampai pencampuran homogen dengan waktu 2 hingga 3 menit. Kemudian ukuran ketebalan lembaran kompon ditentukan 
$2 \mathrm{~mm}$, selanjutnya diletakkan diatas plastik transparan. Kompon dibuat menjadi vulkanisat, di masukkan dalam cetakan, dipress pada suhu $145^{\circ} \mathrm{C}$ selama 5 menit.

\section{Pengukuran sifat fisik vulkanisat}

Ketahanan usang vulkanisat meliputi, kekerasan, tegangan putus dan perpanjangan putus yang dihasilkan dari proses pencampuran (compounding). Pengujian sifat mekanik menggunakan Durometer Frank Shore D untuk pengujian kekerasan, sesuai ASTM D.2240-15, pengujian tegangan putus dan perpanjangan putus dilakukan menggunakan tensometer Lloyd 2000R menurut ASTM D 412-16. Ketahanan usang dilakukan pada suhu $72{ }^{\circ} \mathrm{C}$ dalam oven pengusangan selama 5 (lima) hari mengacu ASTM D 573-04.

\section{HASIL DAN PEMBAHASAN}

\section{Karakteristik Arang Aktif Tempurung Kelapa \\ Karbon Terikat}

Pirolisis arang selain abu menghasilkan karbon dan zat-zat menguap pada pori-pori arang. Penentuan kandungan karbon dilakukan dengan cara uji karbon terikat setelah proses karbonasi dan aktivasi. Kadar karbon terikat yang semakin tinggi merupakan bahan baku yang baik digunakan dalam pembuatan arang aktif (Siregar et al, 2015). Perhitungan karbon terikat berdasarkan selisih kadar zat mudah menguap dan kadar abu (Jamilatun, 2014., Sahara et al, 2017). Hasil analisa karbon yang terikat terlihat bahwa fixed karbon dari karbon aktif dihasilkan kandungan karbon sangat tinggi. Nilai kadar karbon terikat sebesar $80 \%$, dimana nilai tersebut sesuai persyaratan arang aktif sesuai SNI 06- 3730-1995, tentang kualitas arang aktif yaitu minimal $65 \%$.

\section{Karakteristik Vulkanisat Karet \\ Karakteristik Mekanik Vulkanisat Karet Sebelum Pengusangan}

Hasil uji karakteristik mekanik vulkanisat diuraikan pada Tabel 2.

Tabel 2. Karakteristik mekanik vulkanisat karet sebelum pengusangan

\begin{tabular}{|c|c|c|c|}
\hline \multirow{2}{*}{ Karakterisitik mekanik } & \multicolumn{2}{|c|}{$\begin{array}{l}\text { Perbandingan } \\
\text { ATK/CB (phr) }\end{array}$} & \multirow[b]{2}{*}{$45 / 0$} \\
\hline & $0 / 45$ & $\begin{array}{l}22,5 / \\
22,5\end{array}$ & \\
\hline Kekerasan (Shore A) & 62 & 68 & 61 \\
\hline Tegangan Putus (MPa) & 34 & 36 & 30 \\
\hline Perpanjangan Putus (\%) & 500 & 530 & 490 \\
\hline
\end{tabular}

Tabel 2, menunjukkan bahwa hasil pengujian karakterisitk mekanik vulkanisat karet tertinngi sebelum pengusangan, pada perlakuan variasi ATK/CB masing- masing 22,5 phr dan nilai vulkanisat karet pada perlakuan variasi jumlah ATK/CB 45/0 phr, menunjukkan nilai terendah. Nilai kekerasan vulkanisat tertinggi, yaitu 68 Shore A. Interaksi antara bahan pengisi dengan molekul karet disebabkan adanya gugus hidroksil pada permukaan ATK. Menurut Budiono et al (2010), arang tempurung kelapa yang telah diaktivasi memiliki gugus aktif hidroksil $(\mathrm{OH})$. Bahan pengisi yang semakin banyak akan membuat ruang kosong yang semakin banyak pada bahan pengisi, sehingga moleku karet dapat mengisi ruang kosong tersebut, akibatnya terjadi pengumpulan atau penumpukan partikel karet. Hal ini menjadikan lemahnya interaksi antara bahan pengisi dan molekul karet, dan mengakibatkan terjadiya penurunan elastisitas seperti tegangan putus, perpanjangan putus dan kekerasan, (Huseinsyah dan Zakaria, 2011).

\section{Sifat Mekanik Vulkanisat Setelah Pengusangan}

Ketahanan vulkanisat karet terhadap pengusangan dianggap sebagai persyaratan penting untuk kinerja produk yang lebih baik. Kekerasan, tegangan putus dan perpanjangan putus digunakan untuk 
mengevaluasi kemampuan material alami yang digunakan dalam pembuatan vulkanisat karet dalam menghambat pengusangan vulkanisat karet.

\section{Kekerasan}

Gambar 1 menunjukkan pengaruh variasi ATK/CB terhadap kekerasan vulkanisat.

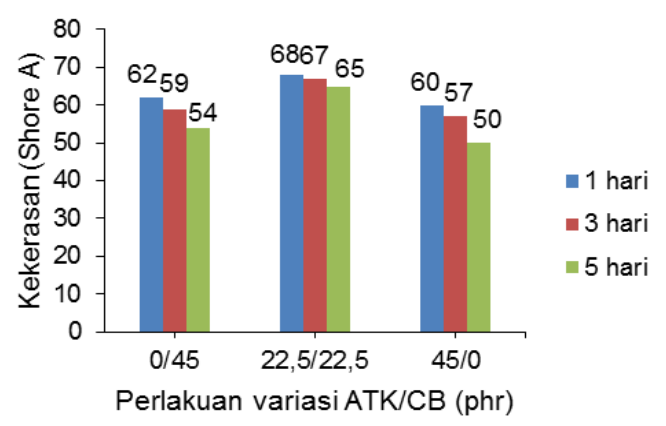

Gambar 1. Pengaruh perlakuan bahan pengisi terhadap kekerasan vulkanisat karet

Nilai tertinggi kekerasan kompon karet setelah pengusangan berdasarkan Gambar 1, pada perlakuan variasi ATK/CB 22,5/22,5, untuk masingmasing pengusangan 1 hari, 3 hari dan 5 hari. yaitu 68 Shore $A, 67$ Shore $A$ dan 65 Shore $A$, sedangkan nilai terendah pada perlakuan variasi ATK/CB 45/0 phr, untuk pengusangan 1 hari, 3 hari dan 5 hari, yaitu masing-masing 60 Shore A, 57 Shore A dan 50 Shore A. Nilai kekerasan vulkanisat karet berbanding terbalik dengan waktu pengusangan. Nilai kekerasan vulkanisat karet semakin menurun dengan meningkatnya waktu pengusangan. Selama pengusangan proses oksidasi dan degradasi akan lebih cepat terjadi dengan adanya panas. Namun, pada pada perlakuan konsentrasi ATK/CB 22,5/22,5 penurunan kekerasan tidak terlalu rendah untuk semua perlakuan lama pengusangan. Hal ini dapat dimungkinkan bahwa, sifat elastisitas vulkanisat karet setelah pengusangan relatif stabil, dengan adanya bahan pengisi yang mampu mempertahankan elastisitas vulkanisat karet. Penambahan MNR sebagai coupling agent sebagai jembatan penghubung interaksi bahan pengisi dengan molekul karet. Selain itu, MNR juga memiliki kemampuan untuk meningkatkan adhesi bahan pengisi dengan matrinya. Reaksi antara MNR dengan ATK/CB menghasilkan ikatan kimia yang kuat, akibatnya terjadi peningkatan kepadatan silang (Katueangngana et al, 2016) dan ketahanan panas karet mengalami peningkatan (Choi and Choi, 2006), akibatnya kekerasan vulkanisat karet mengalami penurunan setelah pengusangan, nilainya tidak jauh berbeda dengan nilai kekerasan sebelum pengusangan. Penggunaan coupling agent MNR memiliki gugus $\mathrm{O}=\mathrm{C}$, dapat mengubah permukaan penguat $\mathrm{CB}$ sehingga mampu saling berikatan dengan ATK yang mengandung gugus $\mathrm{OH}$ pada permukaan ATK, sehingga ATK/CB menjadi lebih kompatibel dengan molekul karet yang hirdifobik (Ismail et al, 2005).

\section{Tegangan Putus}

Tegangan putus vulkanisat karet setelah pengusangan menurun untuk semua perlakuan. Tegangan putus setelah pengusangan terdapat pada Gambar 2.

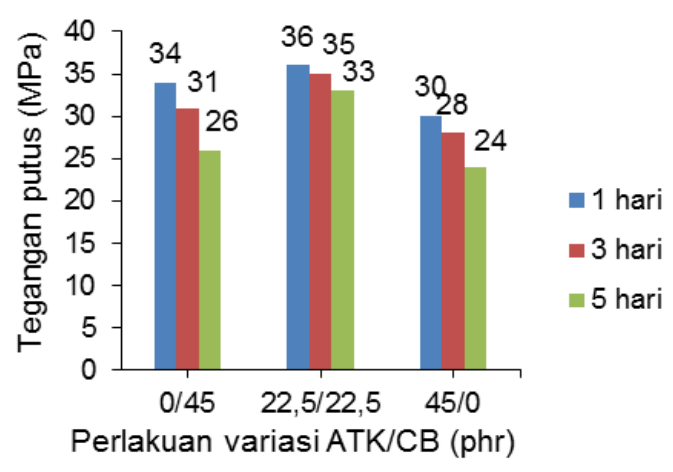

Gambar 2. Pengaruh perlakuan bahan pengisi terhadap tegangan putus vulkanisat karet

Berdasarkan Gambar 2, nilai tegangan putus vulkanisat karet tertinggi pada perlakuan konsentrasi ATK/CB 22,5/22,5, untuk pengusangan 1 hari, 3 hari dan 5 hari, yaitu $36 \mathrm{MPa}, 35 \mathrm{MPa}$ dan $33 \mathrm{MPa}$. Penurunan nilai tegangan putus dengan meningkatnya waktu penyimpanan, untuk perlakuan 
konsentrasi ATK/CB 22,5 phr tidak signifikan, hal ini menunjukkan adanya interaksi antarmuka yang lebih stabil antara bahan pengisi dan matriks. MNR berfungsi sebagai coupling agent yang berinteraksi dengan bahan pengisi dan matriks karet, yang dapat meningkatkan sifat elastis karet (Dechojarassri et al, 2017). Segmen MNR (NR-CH) membentuk ikatan hidrogen dan ikatan ester dan gugus hidroksil dari bahan pengisi di area antar muka (Artchomphoo, J and Rattanapan, 2013). Adhesi yang lebih kuat dari antarmuka bahan pengisi dan matriks menyebabkan transfer tegangan yang lebih baik dari matrik ke bahan pengisi, sehingga kekuatan tarik yang tetap tinggi setelah pengusangan.

Perlakuan bahan pengisi ATK/CB 0/45 phr dan 45/0 phr setelah pengusangan mengalami penurunan yang cukup signifikan. Chong et al., (2010), menjelaskan bahwa penurunan tegangan putus pada biokomposit disebabkan oleh ikatan yang lemah antara matriks dan pengisi.

Permukaan ATK mengandung gugus hidroksil yang bersifat polar dan cenderung membentuk aglomerasi. Aglomerasi bahan pengisi juga menyebabkan dispersi matriks yang tidak merata, sehingga melemahkan tegangan putus material (Ghani et al., 2014). Gugus fungsional OH pada ATK, memiliki kesanggupan berikatan dengan bahan polar membentuk ikatan hidrogen, mengakibatkan lemahnya ikatan bahan pengisi dengan molekul karet (Maan et al.,2015). Adanya CB 45 phr mengakibatkan kemampuan berikatan karet dengan CB menjadi lemah, ronggarongga kosong pada karet lebih banyak terisi CB, akibatnya molekul karet menjadi jenuh, hal ini menyebabkan penurunan tegangan putus.

\section{Perpanjangan Putus}

Nilai perpanjangan putus setelah pengusangan vulkanisat karet disajikan pada Gambar 3.

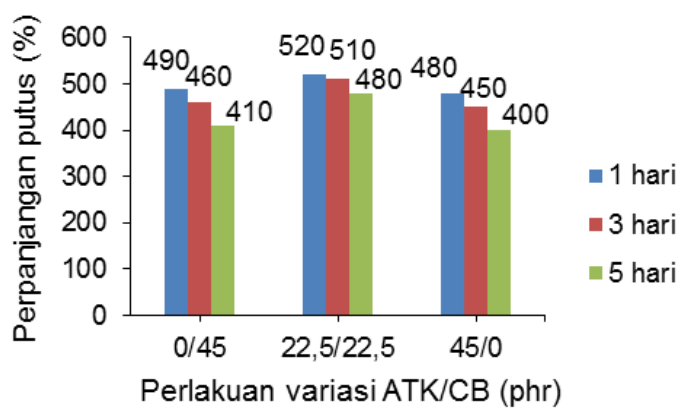

Gambar 3. Pengaruh perlakuan bahan pengisi terhadap Perpanjangan putus vulkanisat karet

Nilai perpanjangan putus tertinggi diperoleh pada perlakuan variasi ATK/CB 22,5/22,5, untuk semua perlakuan lama pengusangan. Penurunan perpanjangan putus pada perlakuan ATK/CB 22,5/22,5 tidak signifikan sebelum dan sesudah pengusangan. Peningkatan dispersi dan adhesi matriks bahan pengisi dan molekul karet, karena adanya MNR, menyebabkan perpanjangan putus menurun dan kekauan karet yang dihasilkan (Daud et al., 2016., Sahakaro and Beraheng, 2008). Selain itu, rapat ikatan silang antar molekul karet meningkat, dimana ketahanan vulkanisat karet pada suhu tinggi dan sinar matahari menjadi lebih baik dengan terbentuknya ikatan silang. Hal ini menyebabkan penurunan perpanjangan putus perlakuan ATK/CB 22,5/22,5, setelah pengusangan, nilainya tidak terlalu jauh berbeda dengan nilai perpanjangan putus sebelum pengusangan.

Variasi ATK/CB 45/0 cenderung menurunkan nilai perpanjangan putus dengan semakin lama pengusangan. Perpanjangan putus yang menurun seiring dengan bertambahnya jumlah ATK dan CB, setelah pengusangan sampai 5 hari. Hal ini disebabkan berkurangnya penguraian dan rantai karet yang terlepas, akibatnya terjadi penurunan ikatan rangkap molekul karet sehingga terjadi kekakuan matriks karet. Selain itu, semakin banyak jumlah bahan pengisi, semakin banyak terbentuknya ikatan sehingga gerak rantai polimer 
terhambat, viskositas kompon dan kekakuan serta elastisitas menurun (Phrommedetch dan Pattamaprom, 2010).

\section{KESIMPULAN}

Bahan pengisi ATK dan CB berpengaruh terhadap karakteristik vulkanisat karet. Hasil analisa karbon yang terikat dihasilkan kandungan karbon sangat tinggi, yaitu sebesar $80 \%$, sesuai spesifikasi mutu arang aktif, yaitu SNI 06-3730-1995, kualitas arang aktif yaitu minimal $65 \%$. Peningkatan konsentrasi ATK/CB dengan adanya MNR dapat meningkatkan sifat mekanik tegangan putus, perpanjangan putus dan kekerasan vulkanisat. Perlakuan konsentrasi ATK/CB 22,5/22,5 memberikan nilai tertinggi ketahanan usang meliputi kekerasan, tegangan putus dan perpanjangan putus.

\section{UCAPAN TERIMA KASIH}

Ucapan terima kasih Penulis kepada Bambang Sugiyono, Rifki dan Wahyu, sehingga kegiatan riset ini berjalan lancar dan selesai sesuai waktu yang ditetapkan.

\section{DAFTAR PUSTAKA}

Artchomphoo, J and Rattanapan, S. (2013). Maleated Natural Rubber as a Coupling Agent for Sawdust Powder Filled Natural Rubber Composites. Advanced Materials Research, 770: 181-184.

Budiono, Suhartana, Gunawan. (2010). Pengaruh Aktivasi Arang Tempurung Kelapa dengan Asam Sulfat dan Asam Fosfat untuk Adsorpsi Fenol (Skripsi). Semarang: Universitas Diponegoro.

Cao, X.V., Ismail, H., Rashid, A.A., Takeichi, T and Vo-Huu, T. (2012). Maleated Natural Rubber as a Coupling Agent for Recycled High Density Polyethylene/Natural Rubber/Kenaf Powder Biocomposites. PolymerPlastics Technology and Engineering. 51: 904-910.

Choi, Sung-Seen and Choi Seok-Ju. (2006). Influence of Silane Coupling Agent on Crosslink Type and Density of
Silicafilled Natural Rubber

Vulcanizates. Bulletin Korean

Chemical Society. 27(9): 1473-476.

Chong, E.L., Ahmad, I., Dahlan, H.M Dan Abdullah, I. (2010). Reinforcement of Natural Rubber/High Density Polyethylene Blends with Electron Beam Irradiated Liquid Natural Rubber-Coated Rice Husk. Radiation Physics and Chemistry. 79(8): 906911.

Daud. S, Ismail. H, Azhar, A. B. (2016). The Effect of 3Aminopropyltrimethyoxysilane (AMEO) as a Coupling Agent on Curing and Mechanical Properties of Natural Rubber/Palm Kernel Shell Powder Composites. Procedia Chemistry. 19(2): 327-334.

Dechojarassri, D, Ratikant, N, Charoenrat, S and Danwanichakul, P. (2017). Mechanical Properties of Natural Rubber Composites Filled with Starch Sludge Compared with Other Waste and Commercial Fillers. International Journal of Chemical Engineering and Applications. 8(3): 210-214.

Ghani, M.H.A., Salleh, M.N., Chen, R.S., Ahmad, S., Yusof, M.R dan Rajendran, N.R. (2014). The Effects of Antioxidants Content on Mechanical Properties and Water Absorption Behaviour of Biocomposites Prepared by Single Screw Extrusion Process. Journal of Polymers. 6 pages.

Husseinsyah, S dan Zakaria, M.M. (2011). The Effect of Filler Content on Properties of Coconut Shell Filled Polyester. Malaysian Polymer Journal. 6(1): 87-97.

Ismail, H., Rusli, A., Rashid, A.A. (2005). Maleated Natural Rubber as a Coupling Agent for Paper Sludge Filled Natural Rubber Composites. Polymer Testing. 24: 856-862.

Katueangngana. K, Tulyapitaka. T, Saetunga. A, Soontaranon. S, Nattapong. N. (2016). Renewable Interfacial Modifier for Silica Filled Natural Rubber Compound. Procedia Chemistry. 19(1): 447-454.

Maan, A., Niyogu, UK., Mehra, DS dan Rattan, S. (2015). Studies on Effect of a Silane Coupling Agent (TESPT) on the Properties of Fly Ash-Natural Rubber Composite. Journal of Polymer Material. 32(1): 47-57.

Marlina, P dan Prasetya, H.A. (2017). Pengaruh Abu Sekam Padi dan Coupling Agent terhadap Ketahanan 
Usang Vulkanisat Bantalan Dermaga. Jurnal Dinamika Penelitian Industri. 28(1): 67-75.

Mohammad, N. N. B., Arsad, A., Rahmat, A.R and Sani, N.S.A. (2015). Effects of Maleated Natural Rubber on Mechanical Properties of Polylactic Acid/Natural Rubber Blends. Materials Science Forum. 819: 284-289

Mulia, A., Bahruddin dan Irdoni. (2015). Pengaruh Kadar Coupling Agent Maleated Natural Rubber terhadap Morfologi dan Sifat Karet Alam Thermoset dengan Filler Abu Sawit/Carbon Black. JOM FTEKNIK. 2: 1-10.

Phrommedetch, S and Pattamaprom, C. (2010). Compatibility Improvement of Rice Husk and Bagasse Ashes with Natural Rubber by Molten-State Maleation. European Journal of Scientific Research. 43(3): 411-416.

Sahakaro, K and Beraheng, S. (2008). Reinforcement of Maleated Natural Rubber by Precipitated Silica. Journal of Applied Polymer Science. 109: 3839-3848.

Sahara, E., Dahliani, N.K dan Manuaba, I.B.P. (2017). Pembuatan dan Karakterisasi Arang Aktif dari Batang Tanaman Gumitir (Tagetes Erecta) Dengan Aktivator $\mathrm{NaOH}$. Jurnal Kimia. 11(2): 174-180.
Sareena, C., Ramesan and Purushothaman, E. (2012). Utilization of Coconut Shell Powder as a Novel Filler in Natural Rubber. Journal of Reinforced Plastics and Composites. 31(8): 533-547.

Siregar, Y.D.I, Heryanto, R, Riyadhi, A, Lestari, T.H and Nurlela. (2015). Karakterisasi Karbon Aktif Asal Tumbuhan dan Tulang Hewan Menggunakan FTIR dan Analisis Kemometrika. Jurnal Kimia VALENSI: Jurnal Penelitian dan Pengembangan IImu Kimia. 1(2): 103-116.

Siti Jamilatun, M. S. (2014). Pembuatan Arang Aktif dari Tempurung Kelapa dan Aplikasinya untuk Penjernihan. Spektrum Industri. 12(1):1-112, 73-82.

Ujianto, O., Noviyanti, R., Wijaya, R, and Ramadhoni, B. (2017). Effect of Maleated Natural Rubber on Tensile Strength and Compatibility of Natural Rubber/Coconut Coir Composite. IOP Conference Series: Materials Science and Engineering 223. 012014: 1-11.

Yusnaini dan Indah Rodianawati. (2014). Produksi dan Kualitas Asap Cair dari Berbagai Jenis Bahan Baku. Prosiding Seminar Nasional Penelitian dan PKM 2014- Sains, Teknologi dan Kesehatan (pp.253-260). Bandung : LPPM Universitas Bandung. 